\title{
Comparative study of sensation and repercussion of tinnitus on the quality of life and craniocervical posture in teachers
}

Marina Stephany Bobroff Mendes ${ }^{1}$ https://orcid.org/0000-0003-2658-5337

Marcelo Yugi Doi ${ }^{1}$ https://orcid.org/0000-0002-1040-9702

Vitoria de Moraes Marchiori² https://orcid.org/0000-0001-6905-3950

Karina Couto Furlanetto ${ }^{1}$ https://orcid.org/0000-0002-7496-7228

Luciana Lozza de Moraes Marchiori ${ }^{1,3}$ https://orcid.org/0000-0002-9026-0468

Universidade Pitágoras Unopar, Londrina, Paraná, Brasil.

Universidade do Vale do Itajaí - Univali, Santa Catarina, Brasil.

Universidade Cesumar - Maringá, Paraná, Brasil.

Conflict of interests: Nonexistent

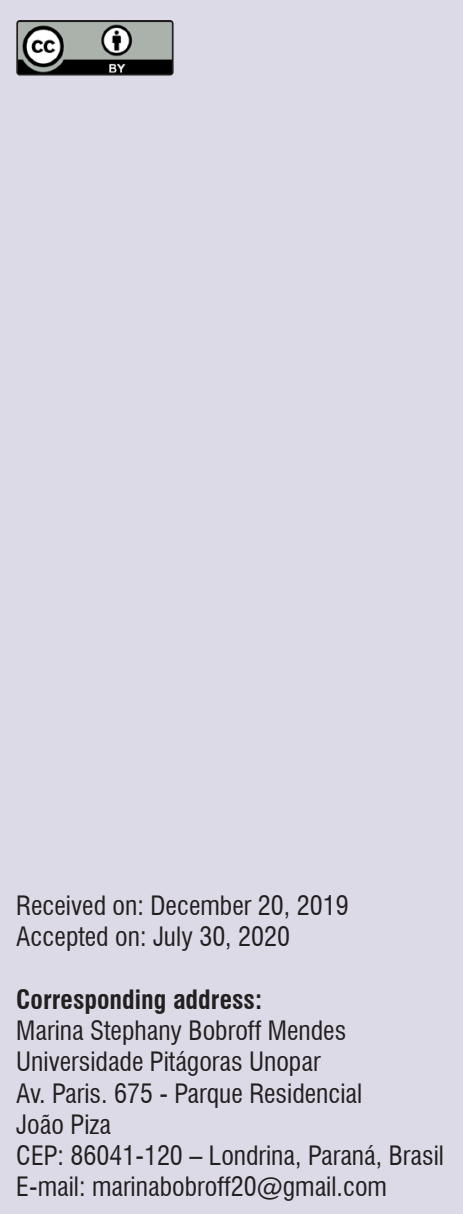

\section{ABSTRACT}

Purpose: to verify whether there is a correlation between tinnitus sensation and repercussion on the quality of life and craniocervical posture in teachers, participating in the Pró-Mestre project.

Methods: a cross-sectional study with a sample of 90 teachers, mean age of 47.70 years, who responded to the Craniocervical Dysfunction Index (CDI), to verify the craniocervical posture, the analog visual scale (AVS), and the Portuguese adaptation of the Tinnitus Handicap Inventory (THI), to investigate tinnitus and its impact on the quality of life. Appropriate statistical tests were applied, by adopting a significance level lower than 0.05 .

Results: out of the 90 teachers, 18 (20\%) had tinnitus. There was a statistically significant difference between the sensation of tinnitus, according to the AVS and the craniocervical posture $(C D I)$ in teachers $(p<0.001)$. There was also an association between tinnitus complaint and right-rotation range of motion, with age and right lateral tilt being independent factors, regarding teachers' tinnitus sensation. In the correlation of the THI (total and domains), there was an association with cervical mobility, only in the left inclination.

Conclusion: since a statistically significant difference was found between the subjective sensation of tinnitus and the craniocervical posture with a correlation between tinnitus sensation and repercussion on the quality of life and craniocervical posture in teachers, these aspects should be considered in the assessment of teachers presented with tinnitus, as well as further studies with a population of teachers, healthy adults, in order to increase the knowledge on the subject.

Keywords: Tinnitus; Posture; Faculty; Health Promotion 


\section{INTRODUCTION}

Teaching is one of the professional activities with the greatest social relevance, especially in basic education. It generally poses challenging working conditions for teachers, with possible implications for their physical and mental health ${ }^{1-3}$, and with an impact on professional performance, which is fundamental for the success of the teaching process ${ }^{2}$. The work environment and psychosocial conditions are important aspects of the multifactorial framework, in which high noise levels have been a recurring complaint of teachers ${ }^{4,5}$. The prevalence of intense noise perception by teachers in Brazilian schools is high, which may cause auditory symptoms 5 .

Tinnitus is an auditory symptom with an abnormal perception of sounds in which there is an auditory sensation perceived by the subject, in the absence of a sound stimulus coming from the environment. It can be either objective or subjective and is usually differentiated based on the person's overall history, in the physical examination, and audiogram ${ }^{6}$. Classifying the type, quality, and intensity of tinnitus is useful to its assessment and treatment - which may include cognitive-behavioral therapy, tinnitus retraining therapy, sound therapy, hearing aids, cochlear implants, pharmacotherapy, and brain stimulation ${ }^{6-11}$.

Patients with tinnitus commonly complain of neck pain and headache, as well. They may also have their symptom influenced by myofascial trigger points in the postural muscles of the cervical region, in the shoulder girdle and masticatory muscles, in which the pain is either spontaneous or caused by movement ${ }^{12}$. Neck and jaw movements can modulate the intensity and tone of tinnitus ${ }^{13}$.

Inadequate posture can cause tensions in the muscles of the cervical region, possibly leading to changes in the inner ear (such as tinnitus), due to changes in the vascularization of that region. Teachers spend a long time standing, which can contribute to the tension of the cervical musculature. Thus, this study aimed to compare the sensation and consequences of tinnitus with the craniocervical posture in public school teachers.

\section{METHODS}

This cross-sectional study is part of a larger project entitled PRÓ-MESTRE - Health, Lifestyle, and Work of Public School Teachers, designed to analyze the health status and lifestyle of teachers from the state education network in Paraná, Brazil, and relate them to aspects of the work process. All participants were informed about the procedures for the evaluations and signed the informed consent form. The study was approved by the Research Ethics Committee of Universidade Norte do Paraná -UNOPAR, Brazil, under protocol no. 742,355.

\section{Sample characterization}

The evaluations in this broad research project took place in three stages, this study being part of the third stage. The flowchart regarding these steps and their respective particularities can be found in Figure 1. For more information about the previous steps, see the reference ${ }^{14}$.

The third stage of the study had 427 teachers selected in the follow-up study ${ }^{14}$. Of these, 341 considered the possibility of continuing with the evaluations in the project. Thus, from September 2015 to June 2017, they were invited to participate in auditory, vestibular, vocal, postural balance, and cervical mobility assessments, in addition to related factors such as physical activity, metabolic and circulatory changes.

The inclusion criteria were all elementary and high school teachers from the municipal state network, of both sexes, aged between 18 and 60 years, who were in the classroom and who were responsible for a subject in the classroom for more than 12 months and who had not had a leave of absence for more than 30 days in the previous 12 months, and who signed the informed consent form. The study excluded those who had cervical pain of known origin and with an image diagnosis (cervical hernia, for example); in addition to those aged over 60 years since tinnitus may reflect the functioning of the individual's body as a whole and is quite prevalent in this age group ${ }^{15}$.

It was not possible to include one teacher who moved to another city, one who had retired, 11 who were away from work, three who did not show up after the third appointment, 57 who had no time available to participate, 32 who were not interested in participating in the evaluations, 140 who were not found after the 5th attempt, six teachers were excluded for not having answered the THI and AVS or for not having participated in the assessment of the cervical skull posture, and a total of 251 who could not be included in the present sample. Thus, 90 teachers $(60$ men and 30 women) were included in the analyses; they attended the scheduled evaluations and met the inclusion and exclusion criteria for this study. 


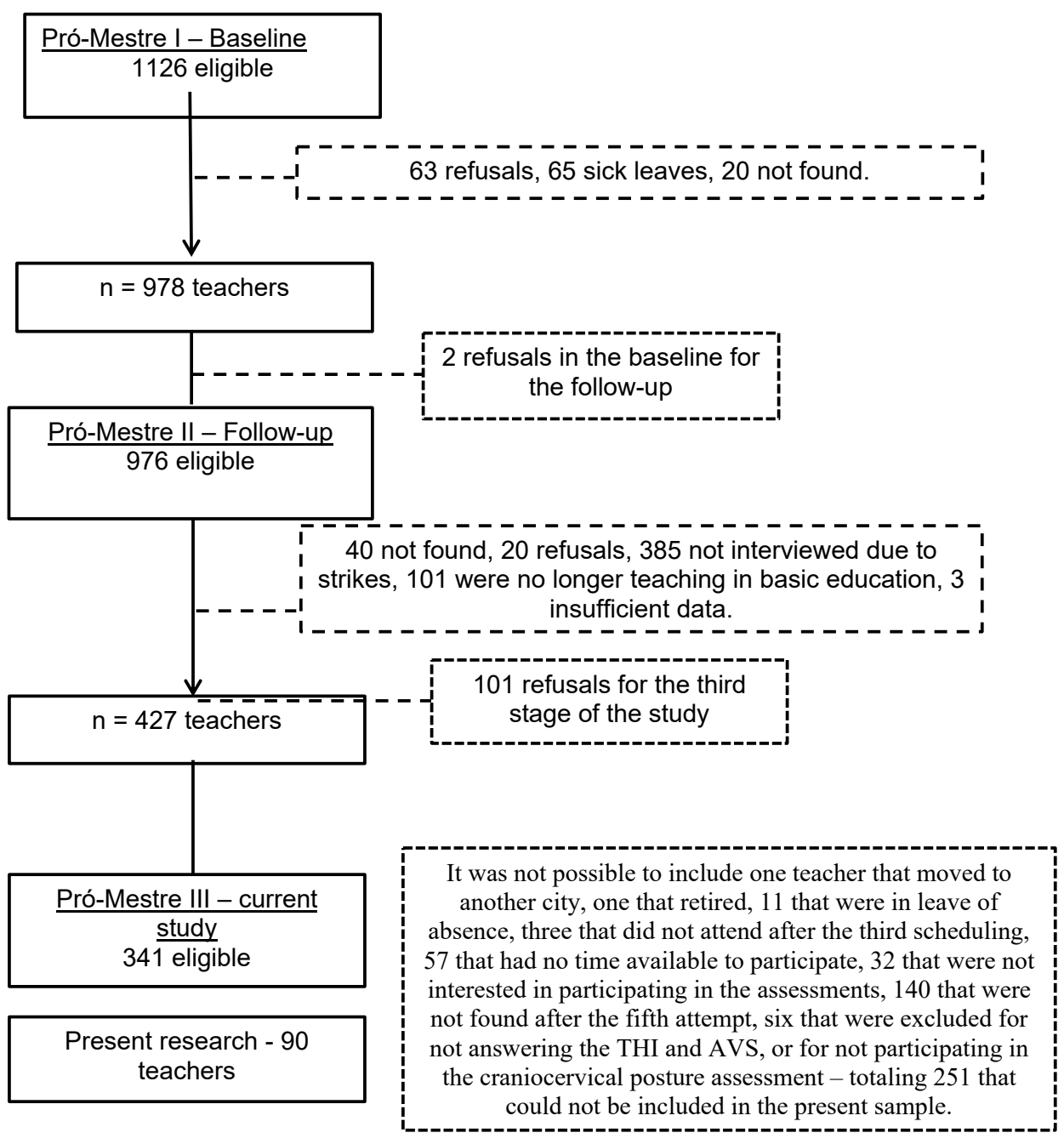

Figure 1. Flowchart of the stages of the Pró-Mestre Project

\section{Data collection}

The initial data had been collected in the previous stages of the Pró-Mestre project.

To conduct the hearing loss research, audiological anamnesis and otoscopy were used to measure the external auditory canal and tympanic membrane, as well as pure-tone audiometry, in a sound booth. This is considered the gold standard for assessing hearing thresholds in adults, in the frequencies from 250 to $8000 \mathrm{kHz}$ with a presentation of pure-tones to exclude those with hearing loss. It was registered on a tonal audiometry sheet and later entered in a database in the Winaudio program to be stored and printed for the patient.

To perform the tinnitus research, data from the audiological anamnesis used in the care routine was used. The AVS was applied to check the degree of inconvenience or discomfort in patients with tinnitus. The patient was asked to give their tinnitus a score from
0 to 10 , with the aid of an appropriate ruler during the audiological anamnesis, when the patient was asked about the sensation of tinnitus. The Tinnitus Handicap Inventory $(\mathrm{THI})^{16}$ was also used. It is an important tool to check the quality of life in patients with tinnitus.

To assess cervical disorders, the $\mathrm{CDI}^{17}$ questionnaire was used to assess cervical mobility, muscle pain, pain during movement, cervical spine joint dysfunction, and posture analysis. Mobility was assessed using the cervical mobility index, described by Wallace and Klineberg ${ }^{18}$.

The index was applied to item " $A$ " using fleximetry, based on the cervical mobility index, described by Wallace and Klineberg. The inspection during the movements of the cervical spine evaluated item "B" in relation to the presence or absence of joint sounds. Item " $C$ " was assessed by bilateral palpation of the neck and jaw muscles. Item " $D$ " was analyzed in all cervical movements, with the presence or absence of 
pain in the execution of the movements. And item "E" was analyzed determined by the postural assessment of the cervical spine using the Postural Assessment Software (SAPO) ${ }^{19}$.

During the neck motion range evaluation, an inspection is made in relation to the presence or absence of joint sounds, which can direct the evaluator in relation to functional impairment - i.e., occasional clicks are probably related to muscle dysfunction, while crackles can be indicative of joint degeneration ${ }^{18}$.

Movement pain is assessed in the flexion, extension, rotation, and lateral inclination neck movements, and muscle pain is analyzed by palpation of the neck and jaw muscles.

The craniocervical posture was assessed by means of a photographic record, using biophotogrammetric analysis using the SAPO software ${ }^{\circledR}(0.68)$, which is a freeware that provides linear and angular measurements ${ }^{19}$.

\section{Statistical analysis}

The prevalence was calculated using the number of individuals with the outcome (tinnitus) divided by the total number of individuals in the sample, with their respective sample errors. The association between the dependent variable (tinnitus) and the categorical independent variables was analyzed using the chi-square test $\left(x^{2}\right)$ for $2 X 2$ contingency tables as needed. The normality of the numerical data was analyzed using the Shapiro-Wilk test and, according to the data distribution, individuals with and without tinnitus were also compared using Student's t-test for independent samples.

For multivariate analysis, Poisson regression with robust variance adjustment was used to identify the factors associated with cases of tinnitus (dependent variable), represented by values of prevalence ratio (PR) and 95\% confidence interval. Only variables with statistical significance (identified in the univariate analysis) were used in this model. Statistical significance was adopted at $5 \%$. The statistical program used was the Statistical Package for the Social Sciences (SPSS 20.0).

Correlation of THI (total) and $\mathrm{THI}$ (domains) with degrees of cervical mobility was performed by statistical analysis of Spearman's correlation coefficient. This coefficient varies from -1 to 1 - the closer it is to 1 or -1 , the stronger the association, the closer it is to zero, the weaker the relationship between the two variables.

The power was calculated using G*Power 3.1.5, comparing the subjective sensation of tinnitus between individuals with and without cervical dysfunction.

\section{RESULTS}

The sample consisted of 90 individuals with a mean age of 48 years, $66.7 \%$ women (60), and $33.3 \%$ men (30). Of these individuals, $20.0 \%$ (18) complained of tinnitus. In addition, $63.3 \%$ of them had cervical dysfunction (Tables 1 and 2).

Table 1. Description of the numerical independent variables

\begin{tabular}{lccc}
\hline Variables & N & Mean & Standard deviation \\
\hline AGE & 90 & 47.7 & 9.39 \\
AOM FLEXION & 90 & 53.28 & 12.026 \\
AOM EXTENSION & 90 & 52.31 & 12.796 \\
AOM ROTATION R & 90 & 61.64 & 15.782 \\
AOM ROTATION L & 90 & 60.76 & 13.938 \\
LAT. INCLINATION R & 90 & 40.89 & 14.357 \\
LAT. INCLINATION L & 90 & 41.78 & 13.98 \\
\hline
\end{tabular}

Legend: $A O M=$ Amplitude of movement; $R=$ right; $L=$ left; $L A T$. = Lateral 
Table 2. Description of the categorical independent variables

\begin{tabular}{lccc}
\hline Variables & N & Porcentage \\
\hline TINNITUS & 90 & Without tinnitus (N=72) & $80.00 \%$ \\
\multirow{2}{*}{ SEX } & & With tinnitus $(\mathrm{N}=18)$ & $20.00 \%$ \\
& 90 & Females $(\mathrm{N}=60)$ & $66.70 \%$ \\
CERVICAL PAIN & & Males $(\mathrm{N}=30)$ & $33.30 \%$ \\
\multirow{2}{*}{ CDI } & 90 & Yes $(\mathrm{N}=37)$ & $41.10 \%$ \\
& \multirow{2}{*}{90} & No $(\mathrm{N}=53)$ & $58.90 \%$ \\
& & Without cervical dysfunction & $36.70 \%$ \\
\hline
\end{tabular}

$\mathrm{N}=$ absolute number $\mathrm{CDI}=$ Craniocervical dysfunction index .

There was no statistical difference between the impact of tinnitus on the quality of life as measured with $\mathrm{THI}$ and craniocervical posture in teachers $(p=0.300)$. On the other hand, there was a statistically significant difference $(<0.0001)$ between the sensation of tinnitus measured with the AVS and the craniocervical posture (CDI) (Table 3).

When performing the the test for risk there was no evidence that led to believe that there is an association between tinnitus and the categorical independent variables (gender, cervical pain, and CDI) since for gender, $p=0.576(p>0.05)$; for cervical pain, $p=$ 0.748 ( $p>0.05)$; and for CDI, $p=0.444(p>0.05)$ (Table 4).

In the analysis of the outcome (tinnitus) and the numerical independent variables, there was an association only for the right rotation $(p=0.025)$ (Table 5).

Table 3. Association between tinnitus and cervical dysfunction

\begin{tabular}{lccccc}
\hline & Wean & $\begin{array}{c}\text { With cervical } \\
\text { dysfunction }\end{array}$ & $\begin{array}{c}\text { Without cervical } \\
\text { dysfunction }\end{array}$ & T & p $<\mathbf{0 . 0 5}$ \\
\hline Subjective tinnitus sensation (AVS) & SD & 3.110 & 0.360 & & \\
& $\mathrm{~N}$ & 5.310 & 1.194 & -4.580 & $<0.0001^{*}$ \\
Interference of tinnitus with the quality & Mean & 3.300 & 5.580 & & \\
of life (THI) & SD & 8.075 & 12.637 & 1.043 & 0.300 \\
\hline
\end{tabular}

AVS = Audio Visual Scale; THI = Tinnitus handicap inventory; DP = Standard deviation; $N=$ Number of individuals; $T=$ Independent t-test value.

Table 4. Association between tinnitus and the categorical independent variables studied

\begin{tabular}{llccc}
\hline \multirow{2}{*}{ Variables } & & With tinnitus & Without tinnitus & \multirow{2}{*}{$\mathbf{0}<\mathbf{0 . 0 5}$} \\
\cline { 3 - 4 } & MALES & $\mathbf{N}=\mathbf{1 8}$ & $\mathbf{N}=\mathbf{7 2}$ & \multirow{2}{*}{0.576} \\
\multirow{2}{*}{ SEX } & FEMALES & $\mathrm{N}=7$ & $\mathrm{~N}=23$ & \\
\multirow{2}{*}{ CERVICAL } & YES & $\mathrm{N}=11$ & $\mathrm{~N}=49$ & \multirow{2}{*}{0.748} \\
PAIN & NO & $\mathrm{N}=8$ & $\mathrm{~N}=10$ & \\
\multirow{2}{*}{ CDI } & WITHOUT CERVICAL DYSFUNCTION & $\mathrm{N}=29$ & $\mathrm{~N}=43$ & \multirow{2}{*}{0.444} \\
& WITH CERVICAL DYSFUNCTION & $\mathrm{N}=10$ & $\mathrm{~N}=25$ & $\mathrm{~N}=47$ \\
\hline
\end{tabular}

$\mathrm{N}=$ number of individuals; $\mathrm{CDI}=$ craniocervical dysfunction index; ${ }^{*}$ chi-square. 
Table 5. Association between tinnitus and the numerical independent variables studied

\begin{tabular}{|c|c|c|c|}
\hline \multirow{2}{*}{ Variables } & With tinnitus & Without tinnitus & \multirow{2}{*}{$<0.05 P$} \\
\hline & $N=18$ & $\mathrm{~N}=72$ & \\
\hline AOM FLEXION & $52.50(12.780)^{*}$ & $52.47(11.916)^{*}$ & $0.761 * *$ \\
\hline AOM EXTENSION & $52.00(13.412)^{*}$ & $52.39(12.734) *$ & $0.909 * *$ \\
\hline AOM ROTATION R & $54.22(13.602)^{*}$ & $63.50(15.826)^{*}$ & 0.025 ** \\
\hline AOM ROTATION L & $55.11(15.412)^{*}$ & $62.17(13.288)^{*}$ & $0.054 * *$ \\
\hline LAT. INCLINATION R & $48.72(19.544)^{*}$ & $38.93(12.144)^{*}$ & $0.056^{\star *}$ \\
\hline LAT. INCLINATION L & $46.50(18.125)^{\star}$ & $40.60(12.620)^{*}$ & $0.110 * *$ \\
\hline
\end{tabular}

AOM = Amplitude of movement; $R$ = right; $L=$ left; $L A T$. = Lateral; *values in mean and standard deviation; **Student's t-test for independent samples

Table 6 shows the estimates, by score and interval, of the odds ratios obtained with the stratified analysis and logistic regression, with age and lateral inclination to the right being independent risk factors for tinnitus. In it, each additional year decreases by $10 \%$ the chances of having tinnitus, and each additional degree of movement decreases by $10 \%$ the chances of having tinnitus. There was a significant difference for age $(p=$ $0.007)$ and lateral inclination to the right $(p=0.020)$.

In the group that presented tinnitus, the median score in the total THI was 22 [08-31], while in the functional, emotional, and catastrophic domains, they were 10 [4-14], 7 [2-9] and 3 [0-8], respectively.

When correlating THI (total and domains) with the angulations of the six cervical mobility variables, only the lateral inclination $(L)$ was negatively correlated with the total THI $(r=-0.481 ; p=0.043)$ and with the functional domain THI $(r=0.513 ; p=0.030)$. This demonstrates that the higher the THI score, the lower the cervical mobility.

There was no correlation between the AVS scale and the degree of cervical mobility $(r<-1.21 ; p>2.55)$.

Considering only those who presented tinnitus, $(n=18)$, there was no difference in cervical mobility (no variable) when compared to the group younger or older than 53 years $(\geq 53)$.

The sample was also separated into two groups: with hearing loss $(n=17)$ and without hearing loss $(n=73)$. There was a difference only in age (55 \pm 8 vs $46 \pm 9$ years, respectively; $p<0.0001$ ) and in the left rotation ROM between the groups ( $53 \pm 15$ vs 62 \pm 13 degrees, respectively; $p=0.018$ ). Using only those who presented hearing loss in a sub-analysis, there were moderate correlations between flexion ROM with total THI $(r=0.547 ; p=0.023)$, functional THI $(r=0.566 ; p=0.018)$ and emotional THI $(r=$ $0.528 ; p=0.030$ ). On the other hand, in the analyses with individuals without hearing loss, there were only weak correlations between flexion ROM with total THI $(r=-0.264 ; p=0.024)$, functional THI $(r=-0.241 ; p=$ $0.040)$ and catastrophic THI $(r=-0.276 ; p=0.018)$.

The power was calculated using $G *$ Power 3.1.5. Using the comparison between the subjective sensation of tinnitus in individuals with or without cervical dysfunction, it was found that the study had a power of $99 \%$ with an alpha of 0.05 .

Table 6. Predictive factors for tinnitus

\begin{tabular}{lccccc}
\hline Variables & $\mathbf{B}$ & Standard deviation & $\mathbf{O R}$ & $\mathbf{9 5 \%} \mathbf{~ C l}$ & $\mathbf{p}<\mathbf{0 . 0 5}$ \\
\hline AGE & -0.150 & 0.005 & 0.985 & $0.974-0.996$ & $0.007^{*}$ \\
LAT. INCLINATION R & -0.190 & 0.008 & 0.981 & $0.965-0.997$ & $0.020^{*}$ \\
\hline
\end{tabular}

$\mathrm{B}=$ beta; $\mathrm{OR}=$ odds ratio; Lat. $\mathrm{R}=$ lateral right ${ }^{*}$ odds ratio test. 


\section{DISCUSSION}

In the present study, a statistically significant difference was found between the subjective sensation of tinnitus and the craniocervical posture. This is not in accordance with research carried out in older adults, which found no association between tinnitus and cervical pain and between tinnitus and range of motion restriction ${ }^{20}$. However, this study is in agreement with another study, which demonstrated that in patients with tinnitus, $75 \%$ had an influence on the intensity of tinnitus depending on the head and neck movement ${ }^{21}$.

People with tinnitus report anecdotal difficulties in mental concentration and psychological treatments, which may directly or indirectly affect the individual in their professional and leisure activities, and interfere with family and social relationships ${ }^{22-24}$. In the present study, there was no difference regarding the interference of tinnitus with the quality of life with the craniocervical posture. However, when the THI (total and domains) was correlated with the angulations of the six cervical mobility variables, only the lateral inclination (L) was negatively correlated with the total $\mathrm{THI}$ and the functional domain THI. Thus, these findings should be interpreted with caution, and further studies should be encouraged with healthy adults, and with teachers, with different sensory conditions in order to deepen the knowledge about tinnitus and cervical disorders in this population.

Teachers constitute a peculiar professional class, susceptible to certain health changes since the school constitutes an important environment in the configuration of the teacher's reality of life and aspects related to the conditions and organization of the teaching work, which have repercussions on the health-disease process $^{25}$

A study shows that teachers proved to know the consequences of exposure to noise, but didn't consider it as an occupational risk. Among the investigated effects, the presence of tinnitus, intolerance to loud sounds, anxiety, and headache were related to a worse quality of life with $15.8 \%$ of teachers presenting tinnitus ${ }^{26}$. In the population of this study, $20.0 \%$ of the teachers had tinnitus, which was also related to a worse quality of life.

In relation to the study population, the importance of being a sample arising from a population study is justified, thus demonstrating the actual number of tinnitus sufferers in this population of teachers. The population of this study was composed predominantly of married women with higher education and who taught in elementary school, as in Moreira et al. ${ }^{27}$. The result of taking on excessive roles produces the so-called double shift, which generally constitutes that of professional activity along with household chores, as a mother and housewife. This double shift means an intense workload for women, contributing to the development of diseases, especially those related to stress ${ }^{28}$.

A higher prevalence of tinnitus was found in the present study in women. The studies are controversial regarding the influence of sex on the prevalence of tinnitus. Although some show a slight increase in prevalence in females, others suggest a higher prevalence in males, although statistical significance is rarely achieved. Nonetheless, in a Brazilian study, of 406 patients evaluated in a six-month period, 58\% complained of tinnitus, of which $68 \%$ were female and $32 \%$ were male ${ }^{29}$. A study that endorses a higher prevalence in males highlights as a possible justification the fact that men are more exposed to occupational noise ${ }^{30}$. In the present study, teachers, in general, are exposed to occupational noise levels that could contribute to the onset of tinnitus in this population.

Another study reinforces the importance of research on the relationship of the effects explored, in elementary and high school teachers, with instruments for assessing the quality of life, as well as the causal relationship between them ${ }^{26}$. The results of the present research reinforce this relevance and the importance of future research regarding the quality of life of teachers in general and of those who present tinnitus, in order to create strategies that can reduce the possible symptoms and comorbidities arising from their occupational activities.

It was found that $47.1 \%$ of the study population complained of neck pain, agreeing with studies in which the prevalence of cervical pain in the adult population can vary from 6 to $50 \%^{30}$. Such symptoms are due to several degenerative processes, direct trauma, or due to cumulative microtraumas of postural stress ${ }^{31}$ Studies show that teachers are more susceptible to such problems and generally complain of lower back and neck pain, depression, hearing, and vestibular disorders. These health problems are probably directly or indirectly associated with working conditions and overload to which teachers are generally exposed ${ }^{32,33}$.

Research carried out by a tinnitus research group showed that this symptom also has a strong association with the presence of myofascial trigger points in the head, neck, and shoulder girdle regions. Dysfunction in cervical proprioception can cause tinnitus and 
other otoneurological symptoms ${ }^{12}$. In addition, it was shown that, in patients with tinnitus, $75 \%$ influenced the intensity of tinnitus dependent on head and neck movement ${ }^{21}$. Such researches are in agreement with the present study since in that one a correlation was found between ROM and tinnitus sensation.

Bechter $(2016)^{34}$ explains that tinnitus can be resumed by restricted head postures. The experimental replication of tinnitus (by inclination) points to a prominent role of the upper posterior cervical muscle groups, combining with animal experiments, also in conjunction with other triggering factors, including psychological factors. Such statements are consistent with the present study, as this study found an association between tinnitus sensation and cervical mobility.

As for the analysis of responses to individual items in the tinnitus handicap inventory according to the severity of the tinnitus handicap, the findings of this study are in agreement with the findings of another study. This last one aimed to investigate whether certain aspects of tinnitus tend to disturb people, even when they are not severely affected by tinnitus in various ways. It found that only those who are severely disabled by tinnitus tend to regard it as a terrible disease, and that lack of control and inability to escape are common feelings among many people with tinnitus, from the most severely disabled to the least ones ${ }^{35}$.

$\mathrm{THI}$ is widely used in a clinical context to assess selfreported disadvantages related to tinnitus and to report treatment results. Nevertheless, a study analyzed THI for factors, which provided strong support for a singlefactor structure of the scale, with most items carrying the first factor, and high internal consistency of the total score. In this paper, the abovementioned instrument was chosen, despite the limitation regarding the factorial analysis of its subscales, as it is a widely used instrument in the clinical context ${ }^{36}$.

Recent research has verified tinnitus in teachers. However, it is usually a task involving tinnitus in response to school noise exposure ${ }^{37,38}$. There is still a shortage in the literature of research that verifies associations between posture and craniocervical mobility with tinnitus symptoms in teachers. In the present research, posture and craniocervical mobility were associated with discomfort caused by tinnitus and its interference with the quality of life in teachers. Hence, further studies are warranted regarding the involvement of the said changes in the cortical-striatal circuits involved in the neuropathology of tinnitus in this population.

\section{CONCLUSION}

In the present study, a significant difference was found between the presence/sensation of tinnitus, measured by AVS, and craniocervical posture (CDI). A correlation analysis showed that there is a repercussion of tinnitus on the quality of life and craniocervical posture in teachers.

When the THI (total and domains) was correlated, an association with cervical mobility, only for the left tilt was seen, which demonstrates that the higher the THI score, the lower the cervical mobility. There was also an association of tinnitus with age and the right lateral inclination, which shows that with each additional year and degree of mobility, the chances of having tinnitus decrease.

Therefore, these aspects must be considered in the evaluation of teachers with tinnitus. Also, further studies with a population of healthy adult teachers are necessary, in order to expand the knowledge on the subject.

\section{REFERENCES}

1. Araújo TM, Pinho PS, Masson MLV. Teachers' work and health in Brazil: thoughts on the history of research, strides, and challenges. Cad. Saúde Pública. 2019;35( Suppl 1 ):e00087318.

2. Luz JG, Pessa SLR, Luz RP, Schenatto FJA. Implications of the environment, conditions and organization of work on teacher health: a systematic review. Ciênc. saúde coletiva. 2019;24(12):4621-32.

3. Ceballos AGC, Santos GB. Factors associated with musculoskeletal pain among teachers: sociodemographics aspects, general health, and well-being at work. Rev Bras Epidemiol. 2015;18(3):702-15.

4. Gomes NR, Medeiros AM, Teixeira LC. Self-perception of working conditions by primary school teachers. Rev. CEFAC. 2016;18(1):167-73.

5. Rezende BA, Medeiros AM, Silva AM, Assunção AÁ. Factors associated with perception of loud occupational noise by school teachers in basic education in Brazil. Rev. bras. epidemiol. 2019;22:e190063.

6. Chari DA, Limb CJ. Tinnitus. Med Clin North Am. 2018;102(6):1081-93.

7. Hertzano R, Teplitzky TB, Eisenman DJ. Clinical evaluation of tinnitus. Neuroimaging Clin $\mathrm{N} \mathrm{Am}$. 2016;26(2):197-205. 
8. Sedley W. Tinnitus: does gain explain? Neuroscience. 2019;407:213-28.

9. Marchiori LLM, Doi MY, Marchiori GM, de Souza GV, Poli-Frederico RC, Ciquinato DSA. Interleukin-1 alpha gene polymorphism (IL-1a) and susceptibility to tinnitus in the elderly. Noise Health. 2019;21(99):77-82.

10. Suzuki FAB, Suzuki FA, Yonamine FK, Onishi ET, Penido NO. Effectiveness of sound therapy in patients with tinnitus resistant to previous treatments: importance of adjustments. Braz J Otorhinolaryngol. 2016;82(3):297-303.

11. Arizola HGA, Teixeira AR. Impacto do zumbido em idosos praticantes e não praticantes de exercício físico. ConScientiae Saúde. 2015;14(1):80-8.

12. Rocha CACB, Sanchez TG, Siqueira JTT. Pontosgatilho miofasciais: ocorrência e capacidade de modulação em pacientes com zumbido. Arq Int Otorrinolaringol. 2006;10(3):210-7.

13. Bousema EJ, Koops EA, van Dijk P, Dijkstra PU. Association between subjective tinnitus and cervical spine or temporomandibular disorders: a systematic review. Trends Hear. 2018;22:2331216518800640.

14. Fillis MMA. Percepção de alteração vocal em professores e fatores associados. [Tese]. Londrina (PR): Universidade Estadual de Londrina; 2017.

15. Cribari J, Ribas A, Fonseca VR, Moretti CM, Zeigelboim BS, Martins $\mathrm{J}$ et al. Description of tinnitus and its relation to discomfort level in a group of elderly hearing aid wearers. Int Tinnitus J. 2016;20(1):36-41.

16. Ferreira PEA, Cunha F, Onishi ET, Branco-Barreiro FCA, Ganança FF. Tinnitus handicap inventory: adaptação cultural para o Português Brasileiro. Pró-Fono R. Atual. Científ. 2005;17(3):303-10.

17. Dias ACM, Doi MY, Mesas AE, Fillis MMA, Branco-Barreiro FCA, Marchiori LLM. Translation to Brazilian Portuguese and cultural adaptation of the craniocervical dysfunction index. Int Arch Otorhinolaryngol. 2018;22(3):291-6.

18. Wallace C, Klineberg IJ. Management of craniomandibular disorders. Part 1: a Craniocervical Dysfunction Index. J Orofac Pain. 1993;7(1):83.

19. Sanchez HM, Gusatti N, Sanchez EGM, Barbosa MA. Incidência de dor musculoesquelética em docentes do ensino superior. Rer. Bras. Med. Trab. 2013;11(2):66-75.
20. Moreira MD, Marchiori LLM, Costa VSP, Damasceno EC, Gibrin PCD. Zumbido: possível associação com alterações cervicais em idosos. Int. Arch. Otorhinolaryngol. 2011;15(3):333-7.

21. Björne A. Assessment of temporomandibular and cervical spine disorders in tinnitus patients. Prog Brain Res. 2007;166:215-9.

22. Mohamad N, Hoare DJ, Hall DA. The consequences of tinnitus and tinnitus severity on cognition: a review of the behavioural evidence. Hear Res. 2016;332:199-209.

23. Wu V, Cooke B, Eitutis S, Simpson MTW, Beyea JA. Approach to tinnitus management. Can Fam Physician. 2018 Jul;64(7):491-5.

24. Kratzsch V, Goebel G. Current aspects of tinnitus and depression. HNO. 2018;66(3):188-97.

25. Penteado RZ, Pereira IMTB. Qualidade de vida e saúde vocal de professores. Rev Saúde Pública. 2007;41(2):236-43.

26. Pimentel BN, Fedosse E, Rodrigues NGS, Cruz KS, Santos Filha VAV. Perception of noise, hearing health and quality of life of public school teachers. Audiol. Commun. Res. 2016;21:1-7.

27. Fillis MMA, Andrade SM, González AD, Melanda FN, Mesas AE. Frequency of self-reported vocal problems and associated occupational factors in primary schoolteachers in Londrina, Paraná State, Brazil. Cad. Saúde Pública. 2016;32(1):1-10.

28. Souza CL, Carvalho FM, Araújo TM, Reis EJFB, Lima VMC, Porto LA. Fatores associados a patologias de pregas vocais em professores. Rev Saúde Pública. 2011;45(5): 914-21.

29. Pinto PCL, Hoshino AC, Tomita S. Características dos pacientes com queixa de zumbido atendidos em ambulatório especializado - HUCFF. Cad Saúde Coletiva. 2008;16(3):437-48.

30. Kettler A, Werner K, Wilke HJ. Morphological changes of cervical facet joints in elderly individuals. Eur Spine J. 2007;16(7):987-92.

31. Carvalho CO, Magalhães DAS, Silva Junior JAA, Bicalho LFH, Costa APB, Costa LOP et al. Estudo comparativo das amplitudes de movimento da coluna cervical em idosos com diferentes níveis de aptidão física. Acta Fisiatr. 2006;13(3):347-51 .

32. Vedovato TG, Monteiro I. Health conditions and factors related to the work ability of teachers. Ind Health. 2014;52(2):121-8. 
33. Collado PA, Soria CB, Canafoglia E, Collado SA. Health and working conditions of high school and university teachers in Mendoza: between commitment and emotional distress. Salud Colect. 2016;12(2):203-20.

34. Bechter K, Wieland M, Hamann GF. Chronic cervicogenic tinnitus rapidly resolved by intermittent use of cervical collar. Front Psychiatry. 2016;7(6):43.

35. Handscomb L. Analysis of responses to individual items on the tinnitus handicap inventory according to severity of tinnitus handicap. Am $\mathrm{J}$ Audiol. 2007;15(2):102-7.

36. Doi MY, Tano SS, Schultz AR, Borges R, Marchiori LLM. Effectiveness of acupuncture therapy as treatment for tinnitus: a randomized controlled trial. Braz. j. otorhinolaryngol. 2016;82(4):458-65.

37. Meuer SP, Hiller W. The impact of hyperacusis and hearing loss on tinnitus perception in German teachers. Noise Health. 2015;17(77):182-90.

38. Ehlert K. Perceptions of public primary school teachers regarding noise-induced hearing loss in South Africa. S Afr J Commun Disord. 2017;64(1):e1-e12. 